\title{
PENGARUH POSISI DAUN PADA TANAMAN SIRSAK (Annona muricata Linn.) DAN AKTIVITAS ANTIBAKTERI SECARA IN VITRO
}

\author{
Reski Yalatri Wirastuty ${ }^{1,2}$, Sartini ${ }^{1}$, Subehan Lallo ${ }^{1}$, Gemini Alam $^{1}$, Herlina Rante ${ }^{1}$, Risfah Yulianty ${ }^{1}$ \\ ${ }^{1}$ Fakultas Farmasi, Universitas Hasanuddin, Makassar \\ 2Jurusan D3 Farmasi, STIKES Nani Hasanuddin, Makassar
}

Kata Kunci :
Sirsak (Annona
muricata Linn.),
Aktivitas antibakteri,
Staphylococcus aureus,
Pseudomonas
aeruginosa

Masuk 31-12-2018

Revisi 02-01-2019

Diterima 02-01-2019

Korespondensi

Subehan Lallo

subehan@unhas.ac.id

Copyright

(C) 2018 Majalah Farmasi Farmakologi Fakultas

Farmasi · Makassar

Diterbitkan tanggal 02-01-2019

Dapat Diakses Daring Pada:

http://journal.unhas.ac.id /index.php/mff

\begin{abstract}
ABSTRAK
Daun Sirsak merupakan salah satu tanaman yang memiliki aktivitas sebagai antibakteri. Penelitian ini bertujuan untuk mengetahui pengaruh letak posisi daun dan aktivitas antibakteri. Masing-masing bagian daun sirsak dimaserasi menggunakan etanol 70\% menggunakan perbandingan 1:7 kemudian dilanjutkan pengujian antibakteri, analisis kualitatif menggunakan UFLC. Aktivitas antibakteri menggunakan metode Disc Diffusion Kirby-Bauer menggunakan medium MHA dengan waktu inkubasi selama 24 jam pada suhu $37^{\circ} \mathrm{C}$ terhadap bakteri Staphylococcus aureus dan Pseudomonas aeroginosa. Hasil penelitian menunjukkan bahwa ekstrak pucuk sirsak yang paling baik aktivitas antibakteri terdapat pada bagian pucuk yang memiliki daya hambat terhadap Staphylococcus aureus sebesar 12,73 $\mathrm{mm}$ dan Pseudomonas aeruginosa sebesar 11,83 $\mathrm{mm}$.
\end{abstract}

\section{PENDAHULUAN}

Pencarian obat dan suplemen makanan yang bersumber dari tanaman sangat meningkat pesat dalam beberapa tahun terakhir ini. Penggunaan obat tradisional dalam hal proses penyembuhan dengan menggunakan tanaman digunakan untuk mencegah atau mengobati kondisi menular. Tanaman obat kaya akan berbagai senyawa metabolit sekunder seperi tannin, terpenoid, alkaloid dan flavonoid ditemukan secara in vitro memiiki sifat antimikroba (1)

Pencarian antimikroba dari tanaman sampai saat ini masih terus dilakukan karena banyaknya obatobat antibiotika yang mengalami resistensi. Peningkatan resistensi antibiotika telah banyak dilaporkan, salah satunya Staphylococcus aureus terhadap antibiotika golongan penisilin. Prevalensi infeksi bakteri Staphylococcus aureus sebanyak 233 isolat (9,43\%) (2). Angka kejadian infeksi nosokomial di dunia yang disebabkan oleh bakteri P.aeruginosa sekitar $10-15 \%$ dan sekitar $10-20 \%$ pada unit perawatan intensif (ICU), biasanya terjadi pada pasien septikemia, sistik fibrosis, luka bakar, dan infeksi luka (3). Penggunaan bakteri Staphylococcus aureus karena semakin banyak peningkatan resistensi bakteri terhadap antibiotika. Sedangkan penggunaan Pseudomonas aeruginosa merupakan penyebab pernafasan, lokasi operasi dan infeksi saluran kemih pada pasien dari area perawatan intensif (4).

Salah satu tanaman yang menunjukkan aktivitas antimikroba adalah sirsak (Annona muricata Linn.). Pada daun sirsak terdapat senyawa acetogenins (5), $\beta$-caryophyllene $(13.6 \%), \delta$ cadinene (9.1\%), epi- $\alpha$-cadinol $(8.4 \%), \alpha$-cadinol (8.3\%) (Kossouoh et al., 2007), Bicyclogermacrene $(39,8 \%)(6)$, annomuricine dan muricapentocin (7), hexadecanoic acid $\left(\mathrm{C}_{17} \mathrm{H}_{34} \mathrm{O}_{2}\right)$, and methyl ester of 9-octadecenoic acid ( $\mathrm{Z})\left(\mathrm{C}_{19} \mathrm{H}_{36} \mathrm{O}_{2}\right)(8)$, Genticid acid (9).
Dari beberapa penelitian menunjukkan bahwa ekstrak etanol daun sirsak memiliki aktivitas antibakteri Staphylococcus aureus dengan Kadar Hambat Minimal (KHM) sebesar $128 \mathrm{mg} / \mathrm{ml}$ (Bussmann et al., 2010). Ektsrak etanol 95\% memiliki aktivitas antibakteri terhadap bakteri gram positif (Staphylococcus aureus dan Bacilus subtilis) (9). Ekstrak air memiliki aktivitas antibakteri terhadap Staphylococcus aureus dan Pseudomonas aureus (Taylor, 2002). Fraksi etil asetat daun sirsak memiliki aktivitas antibakteri terhadap Staphylococcus aureus sebesar 29.3 \pm 1.5 $\mathrm{mm}$ dan Pseudomonas aureus sebesar 27.6 \pm 1.2 $\mathrm{mm}$ (10). Ekstrak metanol daun sirsak mempunyai Kadar Hambat Minimal (KHM) terhadap bakteri Staphylococcus aereus sebesar $156 \mu \mathrm{g} / \mathrm{mL}$ dan Pseudomonas aeroginosa sebesar $625 \mu \mathrm{g} / \mathrm{mL}$ (11). Ekstrak etanol daun sirsak menunjukkan aktivitas antibakteri terhadap Pseudomonas aeruginosa sebesar $18 \mathrm{~mm}$ dan Staphylococcus aureus sebesar $18 \mathrm{~mm}$ (12).

Efek farmakologi suatu tanaman obat tergantung pada senyawa kimia yang terkandung di dalam tanaman tersebut. Sementara, kandungan senyawa kimia dalam tanaman dipengaruhi oleh faktor genetik, kondisi lingkungan (tempat tumbuh, iklim), perlakuan selama masa tumbuh, kondisi (umur dan cara panen) (13). Jika dibandingkan dengan penelitian-penelitian sebelumnya, beberapa peneliti menggunakan berbagai jenis pelarut diantaranya metanol, nHeksan dan air. Namun dalam penelitian ini menggunakan pelarut etanol. Dimana Asam gentisat merupakan senyawa hydroquinone yang dapat larut dalam etanol (14).

Berdasarkan latar belakang di atas, maka peneliti tertarik ingin melakukan penelitian tentang pengaruh posisi daun pada tanaman sirsak (Annona muricata Linn.)dan aktivitas antibakteri 
secara in vitro. Dimana bakteri yang digunakan adalah Staphylococcus aureus mewakili bakteri gram positif dan Pseudomonas aeruginosa mewakili bakteri gram negative.

\section{METODE PENELITIAN}

Metode yang digunakan dalam penelitian ini adalah metode eksperimental yang dilakukan dalam beberapa tahap, yaitu pengolahan simplisia, ekstraksi, HPLC, uji aktivitas antibakteri dan pengolahan data. Penelitian ini dilaksanakan pada bulan Maret 2018 bertempat di Laboratorium Fitokimia dan Laboratorium Biofarmaka Pusat Kegiatan Penelitian (PKP) Universitas Hasanuddin Makassar

\section{Bahan}

Bahan - bahan yang digunakan adalah air suling, bakteri uji Staphylococcus aureus ATCC 170718 dan Pseudomonas aeroginosa ATCC 170830, daun sirsak (Annona muricata Linn.) , Kloramfenicol, DMSO, NaCL 0,9\%, kapas, kain kasa steril, medium Muellen Hilton Agar (MHA). Bahan kimia untuk ekstraksi adalah etanol $70 \%$

\section{Cara Kerja}

Cara kerja pembuatan ekstrak yaitu Masing-masing serbuk daun sirsak (Annona muricata Linn.) berdasarkan posisi daun (pucuk, tengah dan pangkal) $250 \mathrm{~g}$ sampel serbuk dimaserasi dengan menggunakan pelarut etanol $70 \%$ dengan perbandingan 1:7. Kemudian ditutup dan didiamkan sambil sesekali diaduk. Proses maserasi dilakukan dengan mengganti pelarut tiap 1x24 jam selama tiga hari. Hasil maserasi dikumpulkan dan disaring. Filtratnya kemudian diuapkan menggunakan rotary evaporator hingga diperoleh ekstrak etanol daun sirsak. Ekstrak kental yang diperoleh ditimbang dan disimpan di dalam desikator sebelum digunakan untuk uji selanjutnya.

Penapisan fitokimia dilakukan untuk mengetahui golongan senyawa yang terkandung dalam ekstrak sirsak. Kandungan yang diperiksa adalah golongan flavonoid, alkaloid, saponin, dan tanin.

Uji aktivitas antibakteri dengan metode Disc Diffusion KirbyBauer dengan metode agar berlapis. Base Layer tidak menggunakan bakteri uji kemudian dibiarkan memadat. Selanjutnya Seed Layer mengandung bakteri uji yang dicampurkan pada medium. Dibiarkan hingga memadat selama kurang lebih 5 menit.

Kertas cakram berdiameter $6 \mathrm{~mm}$ yang steril yang mengandung ekstrak uji ( $2 \mathrm{mg} /$ disc) ditunggu hingga kering kemudian di letakkan pada medium yang telah disiapkan. Sebagai kontrol positif yang digunakan adalah Amokcicillin dan kontrol negatif yang digunakan adalah DMSO $10 \%$. Kertas cakram tersebut kemudian ditempatkan diatas permukaan media sesuai dengan posisi yang ditentukan. Setiap perlakuan dibuat sebanyak 3 kali pengulangan. Media diinkubasi pada suhu $37^{\circ} \mathrm{C}$ selama $1 \times 24$ jam. Selanjutnya diamati zona hambat yang terbentuk dengan melihat zona bening di sekitar cakram.

Pengukuran Sampel menggunakan HPLC. Kolom dimasukkan ke dalam wadah sampel pada instrumen, instrumen dinyalakan dan dipilih metode analisis dengan waktu running sekitar 10-15menit. Sampel yang telah divortex diinjeksikan ke dalam alat HPLC kemudian diukur absorbansinya pada panjang gelombang $246 \mathrm{~nm}$ dan $366 \mathrm{~nm}$. Dihasilkan kromatorgram yang kemudian dianalisis sampel yang diperoleh.

\section{HASIL DAN PEMBAHASAN}

Daun sirsak (Annona muricata Linn.) di bagi atas tiga bagian yaitu pucuk, tengah dan pangkal. Masing-masing simplisia sampel $200 \mathrm{~g}$ di maserasi selama 3 hari dengan pelarut etanol $70 \%$ menggunakan perbandingan 1:7. Selama maserasi dilakukan pengadukan berulang agar kontak antara pelarut dengan bahan lebih optimal sehingga kondisi jenuh yang terlalu cepat dapat dihindari. Maserat yang didapat kemudian diuapkan dengan vacum rotary evaporator. Suhu yang digunakan adalah 58 $\mathrm{C}$ karena titik didih etanol adalah $78,5^{\circ} \mathrm{C}$ dan diharapkan pelarut etanol akan menguap serta senyawa aktif dalam daun sirsak yang sudah tersari tidak rusak oleh suhu yang tinggi. Hasil ekstrak cair yang didapat dari proses evaporasi selanjutnya diuapkan lagi. Ekstrak etanol daun sirsak berwarna coklat, berbau khas konsistensinya kental dan tidak dapat dituang dalam keadaan dingin. Diperoleh ekstrak etanol kental daun pucuk seberat 10,7738 g dengan rendemen $5,386 \%$, ekstrak etanol daun tengah seberat 16, $7068 \mathrm{~g}$ dengan rendamen 8,3535\% dan ekstrak kental daun pangkal seberat 14,6732 g dengan rendamen 7,336\%.

Berdasarkan hasil penapisan fitokimia pada tabel 1 yang dilakukan dapat diketahui bahwa ekstrak etanol daun sirsak mengandung senyawa alkaloid, flavonoid, tanin dan saponin yang ditandai dengan adanya endapan dan terbentuknya warna yang spesifik untuk senyawa-senyawa tersebut.

\begin{tabular}{lccc}
\multicolumn{4}{l}{ Tabel 1. Hasil penapisan fitokimia daun sirsak } \\
\hline \multirow{5}{*}{ Senyawa } & Ekstrak & Ekstrak & Ekstrak \\
& Pucuk & Tengah & Pangkal \\
& Daun & Daun & Daun \\
& Sirsak & Sirsak & Sirsak \\
\hline Flavonoid & + & + & + \\
Alkaloid & + & + & + \\
Saponin & + & + & + \\
Tanin & + & + & + \\
\hline
\end{tabular}

Menurut Rarassari et al (2016) analisis fitokimia pada ekstrak etil asetat daun Annona muricata Linn. memiiliki kandungan senyawa saponin, tanin/polifenol, flavonoid, dan steroid. Menurut Vijayameena (2013) menyebutkan bahwa ekstrak etanol daun sirsak mengandung alkaloid, flavonoid, glikosida, saponin dan tannin. Penelitian lain juga menyebutkan ekstrak metanol daun sirsak mengandung senyawa golongan fenolik dan terpenoid/steroid, ekstrak etil asetat daun sirsak mengandung senyawa golongan alkaloid dan ekstrak etil asetat daun sirsak mengandung senyawa terpenoid/steroid (15)

Penentuan hasil uji aktivitas antibakteri ekstrak etanol daun sirsak dilakukan dengan metode difusi agar menggunakan disc cakram. Menggunakan kontrol negative DMSO, kontrol positif Amoxicillin, dan konsentrasi larutan uji 10\% (b/v). Diameter yang berada disekitar disc diukur dengan tujuan mengukur kekuatan hambatan obat terhadap bakteri yang diuji. Zona hambat bening di sekitar kertas cakram yang terbentuk diukur menggunaka jangka sorong. Hasil pengukuran diameter rata-rata daerah hambatan pertumbuhan bakteri Staphylococcus aures dan Pseudomonas aeroginosa dapat dilihat pada Tabel 2 dan Gambar 1.

Berdasarkan hasil pengukuran aktivitas antibakteri terhadap Staphylococcus aureus yang terlihat pada Tabel 2. diperoleh ekstrak daun pucuk sirsak memiliki diameter hambat sebesar $12.73 \mathrm{~mm}$ dengan standar deviasi sebesar 0.25 dan pada 
Tabel 2. Hasil Pengujian Antibakteri Ekstrak Etanol Daun Sirsak

\begin{tabular}{|c|c|c|c|c|c|c|}
\hline \multirow[t]{2}{*}{ No } & \multirow[t]{2}{*}{ Bakteri } & \multirow[t]{2}{*}{ Bagian } & \multicolumn{3}{|c|}{$\begin{array}{c}\text { Diameter Zona } \\
\text { Hambat }\end{array}$} & \multirow{2}{*}{$\begin{array}{l}\text { Rata } \\
\text { Rata }\end{array}$} \\
\hline & & & I & II & III & \\
\hline \multirow{3}{*}{1} & \multirow{3}{*}{$\begin{array}{c}\text { Staphylo- } \\
\text { coccus } \\
\text { aureus }\end{array}$} & Pucuk & 13,00 & 12,5 & 12,7 & $\begin{array}{l}12,73 \\
\pm 0,25\end{array}$ \\
\hline & & Tengah & 8,88 & 12,7 & 9,6 & $\begin{array}{l}10,34 \\
\pm 2,03\end{array}$ \\
\hline & & Pangkal & 12,5 & 9,83 & 10,8 & $\begin{array}{l}11,04 \\
\pm 1,35\end{array}$ \\
\hline \multirow{3}{*}{2} & \multirow{3}{*}{$\begin{array}{l}\text { Pseudo- } \\
\text { monas } \\
\text { aeroginosa }\end{array}$} & Pucuk & 11,2 & 11,5 & 12,8 & $\begin{array}{l}11,83 \\
\pm 0,65\end{array}$ \\
\hline & & Tengah & 10,0 & 12,2 & 10,2 & $\begin{array}{r}10,8 \\
\pm 1,21\end{array}$ \\
\hline & & Pangkal & 11,2 & 12,1 & 10,0 & $\begin{array}{r}11,1 \\
\pm 1,05\end{array}$ \\
\hline
\end{tabular}

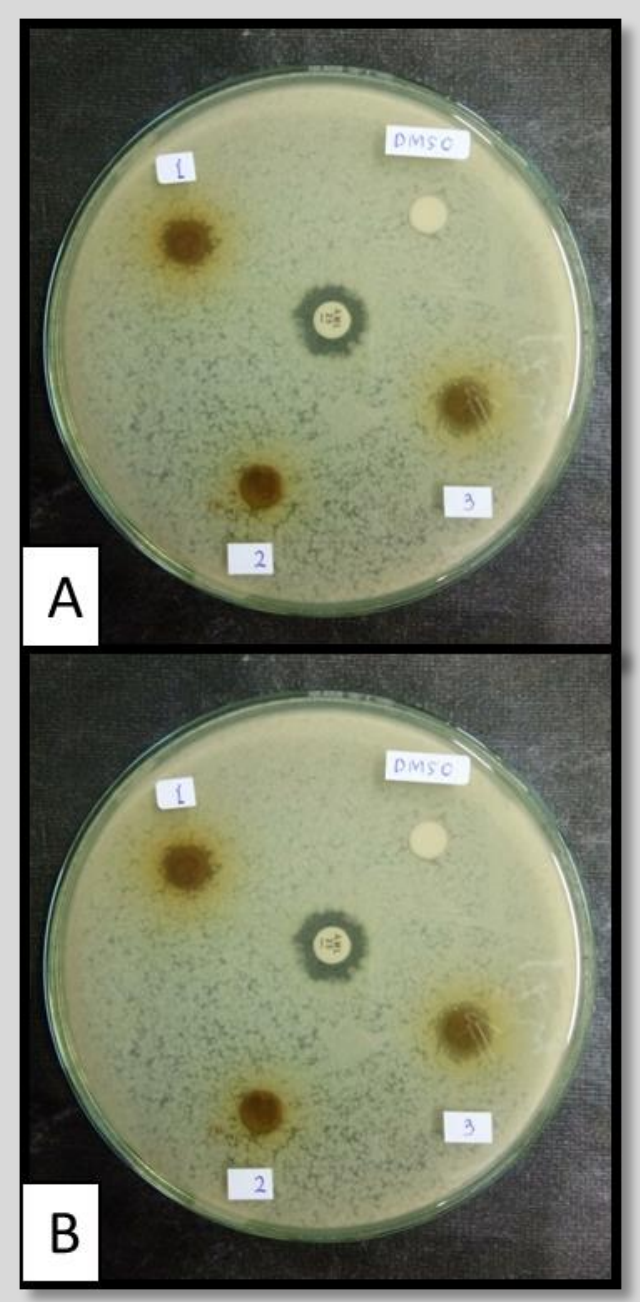

Keterangan:

$1=$ Ekstrak Pucuk Daun Sirsak

2 = Ekstrak Tengah Daun Sirsak

$3=$ Ekstrak Pangkal Daun Sirsak

Gambar 2. Hasil Pengujian Aktivitas Antibakteri Terhadap (A) Bakteri Staphylococcus aureus dan (B) Bakteri Pseudomonas aeroginosa.

ekstrak daun tengah sirsak memiliki diameter hambat sebesar $10.34 \mathrm{~mm}$ dengan standar deviasi sebesar 2.03 dan ekstrak daun pangkal sirsak diameter hambat $11.04 \mathrm{~mm}$ dengan nilai standar deviasi sebesar 1.36. Sedangkan hasil pengukuran aktivitas antibakteri terhadap Pseudomonas aeroginosa diperoleh ekstrak daun pucuk sirsak memiliki diameter hambat sebesar $11.83 \mathrm{~mm}$ dengan standar deviasi sebesar 0.65 dan pada ekstrak daun tengah sirsak memiliki diameter hambat sebesar $10.8 \mathrm{~mm}$ dengan standar deviasi sebesar 1.21 dan ekstrak daun pangkal sirsak diameter hambat $1.1 \mathrm{~mm}$ dengan nilai standar deviasi sebesar 1.05 . Perbedaan tersebut tidak signifikan dan hasil uji statistik didapatkan bahwa nilai yang didapat $>0.05$ artinya posisi daun (pucuk, tengah dan pangkal) tidak terdapat perbedaan. Berdasarkan data diatas dapat disimpulkan bahwa ekstrak pucuk daun sirsak yang memiliki aktivitas antibakteri yang paling bagus.

Aktivitas antibakteri dapat dipengaruhi oleh beberapa faktor yang dibagi menjadi faktor biologis dan faktor teknis. Faktor teknis sebagian besar dapat dikendalikan oleh peneliti namun faktor biologis tidak dapat dikendalikan oleh peneliti. Brooks et al. (2008) juga menyatakan bahwa aktivitas antibakteri dipengaruhi beberapa faktor yaitu konsentrasi ekstrak, kandungan senyawa antibakteri, daya difusi ekstrak, dan jenis bakteri yang dihambat

Beberapa faktor yang juga mempengaruhi mutu ekstrak yaitu faktor kimia seperti jenis dan jumlah senyawa kimia, metode ekstraksi dan pelarut yang digunakan. Selain itu, adanya variasi biologis, misalnya tempat asal daun sirsak yang digunakan. Faktor-faktor lingkungan seperti suhu udara, kelembapan relatif, radiasi matahari, angin, suhu tanaman, ketersediaan air, ketercukupan cahaya dalam proses fotosintesis sangat memengaruhi fungsi fisiologis, bentuk anatomis, dan siklus hidup tumbuhan. Pada daun yang masih muda, mengandung zat-zat yang bersifat antibakteri, sedangkan pada daun yang sudah tua sudah mulai ada yang rusak (16). Daun sirsak memiliki kemampuan daya hambatnya pada bakteri gram positif lemah, sehingga ekstrak ini dapat dianggap bersifat bakteriostatik (17)

Berdasarkan penelitian yang dilakukan Devitasari dkk (2018), diperoleh bahwa ekstrak daun sirsak muda ketiga dari pucuk mempunyai efek antibakteri terhadap Staphylococcus aureus.

Waktu retensi $\left(t_{R}\right)$ adalah waktu yang dibutuhkan oleh suatu analit untuk melewati kolom KCKT sampai terdeteksi oleh detektor. Dalam sistem KCKT pada kondisi tertentu, suatu analit akan memberikan waktu retensi yang spesifik. Sehingga apabila terdapat dua senyawa yang mempunyai waktu retensi $\left(t_{R}\right)$ yang sama atau mirip, maka dapat dikatakan bahwa kedua senyawa tersebut adalah sama (18).

Berdasarkan data analisis profil kromatogram ekstrak etanol daun sirsak dengan menggunakan UFLC pada panjang gelombang $254 \mathrm{~nm}$ menunjukkan waktu retensi dan luas area yang berbeda dari masing-masing ekstrak yang dapat dilihat pada gambar 2 .

Dari kromatogram ekstrak pucuk, tengah dan pangkal sirsak (Gambar 2), tR yang dimiliki ekstrak daun pucuk sirsak, ekstrak daun tengah sirsak dan ekstrak daun pangkal sirsak adalah 8,7 menit dengan luas area pada ekstrak daun pucuk sirsak 81416, ekstrak tengah daun sirsak 137731 dan ekstrak pangkal daun sirsak 6169, sehingga dapat dipastikan dalam sampel ekstrak daun pucuk sirsak, ekstrak daun tengah sirsak dan ekstrak daun pangkal sirsak memiliki senyawa yang sama.

Pada menit ke-13, muncul area puncak pada ekstrak pucuk daun sirsak yang hampir sama dengan area puncak ekstrak tengah dan pangkal daun sirsak. Diduga adanya komponen senyawa yang sama pada masing-masing ekstrak. Namun, dari ketiga bagian dari ekstrak daun sirsak tersebut yang memiliki komponen senyawa dengan konsentrasi tinggi pada ekstrak pucuk daun sirsak. Hal ini dapat dilihat dari luas area pada ekstrak pucuk daun sirsak lebih luas dibanding yang lain. 


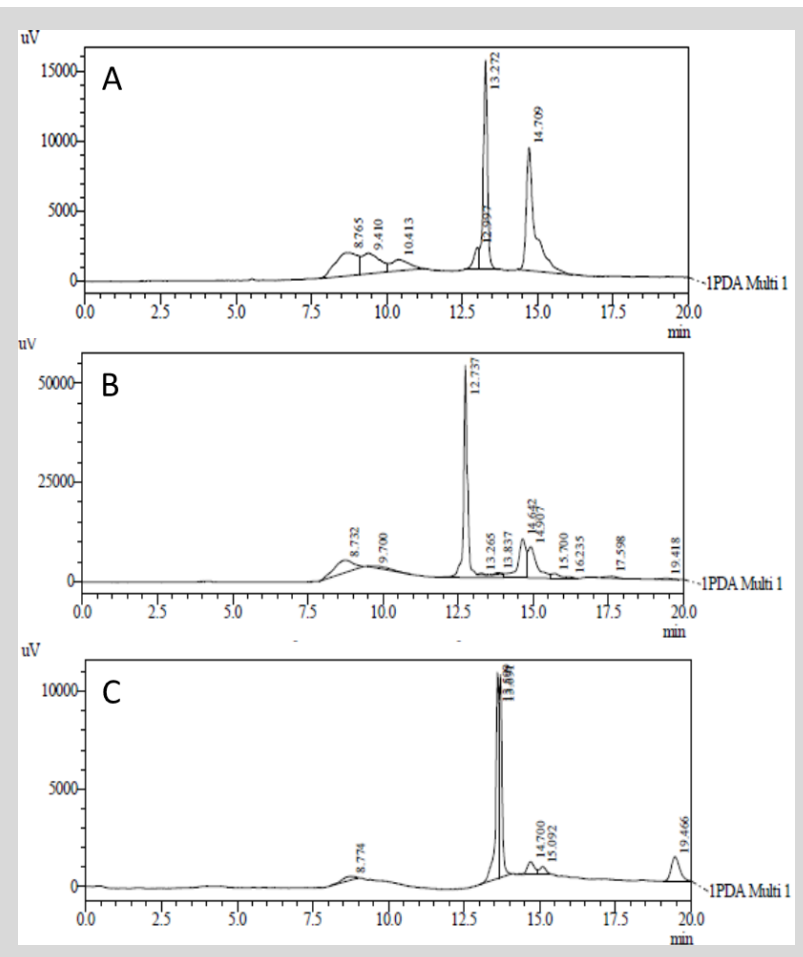

Gambar 2. Profil Kromatogram Ekstrak Etanol Daun Sirsak Pada Panjang Gelombang $254 \mathrm{~nm}$ (A) Pucuk, (B) Tengah, (C) Pangkal dengan fase diam Oktadesilsilan dan fase gerak Acetonitrit: Metanol: Air (40:20:40).

Tabel 3. Hasil Perbandingan Waktu Retensi dan Luas Area Ekstrak Etanol Daun Sirsak (Annona muricata Linn.) Pada Panjang Gelombang $254 \mathrm{~nm}$

\begin{tabular}{cccc}
\hline $\begin{array}{c}\text { Waktu } \\
\text { Retensi } \\
\text { (Menit) }\end{array}$ & Pucuk & Tengah & Pangkal \\
\cline { 2 - 4 } & 81416 & 137731 & 6169 \\
8.7 & 63818 & - & - \\
9.4 & - & 23967 & - \\
9.7 & 34954 & - & - \\
10.4 & - & 498059 & - \\
12.7 & 18438 & - & - \\
12.9 & 141159 & 4070 & - \\
13.2 & - & - & 78120 \\
13.5 & - & - & 64388 \\
13.6 & - & 4998 & - \\
13.8 & - & 184720 & - \\
14.6 & 17716 & - & 10269 \\
14.7 & - & 158391 & - \\
14.9 & - & - & 5186 \\
15.1 & - & 22908 & - \\
15.7 & - & 4486 & - \\
16.2 & - & 10347 & - \\
17.5 & - & 6119 & 24569 \\
19.4 & & &
\end{tabular}

Pada menit ke-14, muncul area puncak pada masing-masing ekstrak. Diduga adanya komponen senyawa yang sama pada masing-masing ekstrak dan yang memiliki konsenttrasi tinggi, dilihat dari luas area adalah ekstrak pucuk daun sirsak.

Berdasarkan data analisis profil kromatogram ekstrak etanol daun sirsak dengan menggunakan UFLC pada panjang gelombang $366 \mathrm{~nm}$ menunjukkan waktu retensi dan luas area yang berbeda dari masing-masing ekstrak yang dapat dilihat pada gambar 3 .

Pada menit ke-13, muncul area puncak pada ekstrak pucuk daun sirsak yang hampir sama dengan area puncak ekstrak tengah dan pangkal daun sirsak. Diduga adanya komponen senyawa yang sama pada masing-masing ekstrak. Namun, dari ketiga bagian dari ekstrak daun sirsak tersebut yang memiliki komponen senyawa dengan konsentrasi tinggi pada ekstrak pucuk daun sirsak. Hal ini dapat dilihat dari luas area pada ekstrak pucuk daun sirsak lebih luas dibanding yang lain.

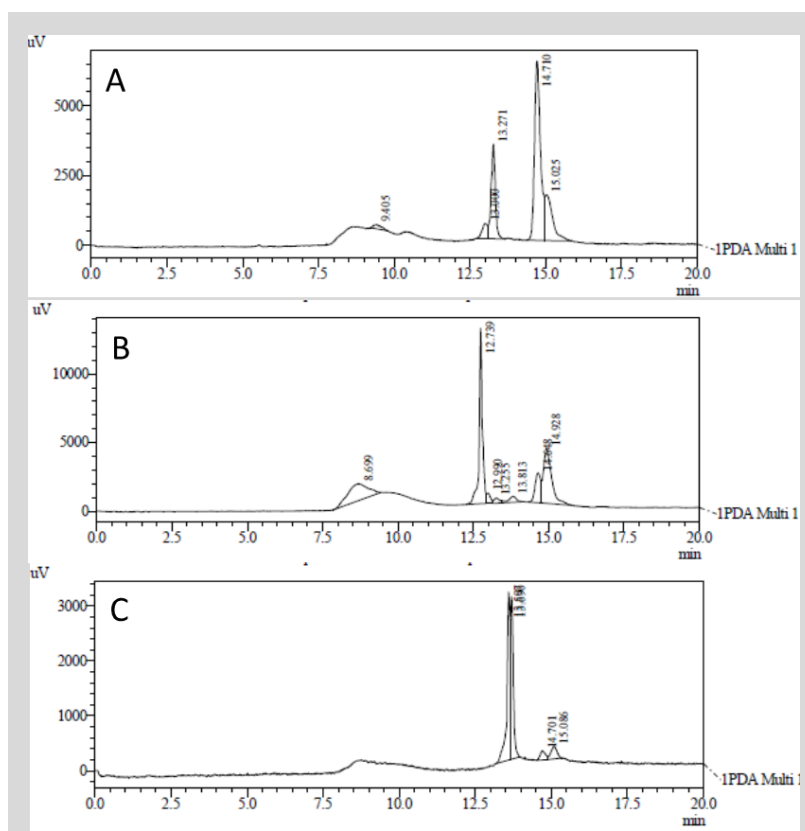

Gambar 3. Profil Kromatogram Ekstrak Etanol Daun Sirsak Pada Panjang Gelombang $366 \mathrm{~nm}$ (A) Pucuk, (B) Tengah dan (C) Pangkal dengan fase diam Oktadesilsilan dan fase gerak Acetonitrit: Metanol: Air (40:20:40).

\begin{tabular}{cccc}
\multicolumn{4}{c}{ Tabel 4. Hasil Pengujian Antibakteri Ekstrak Etanol Daun Sirsak } \\
\hline \multicolumn{3}{c}{$\begin{array}{c}\text { Waktu } \\
\text { Retensi } \\
\text { (Menit) }\end{array}$} & Puas Area \\
\cline { 2 - 4 } & Pucuk & Tengah & Pangkal \\
\hline 8.6 & - & 58741 & - \\
9.4 & 2807 & - & - \\
12.7 & - & 95872 & - \\
12.9 & - & 6320 & - \\
13.0 & 6659 & - & - \\
13.2 & 32687 & 4517 & - \\
13.5 & - & - & 22320 \\
13.6 & - & - & 17981 \\
13.8 & - & 7943 & - \\
14.6 & - & 28141 & - \\
14.7 & 88467 & - & 2054 \\
14.9 & - & 75174 & - \\
15.0 & 28895 & - & 3080 \\
\hline
\end{tabular}

Pada menit ke-14, muncul area puncak pada masing-masing ekstrak. Diduga adanya komponen senyawa yang sama pada masing-masing ekstrak dan yang memiliki konsentrasi tinggi, dilihat dari luas area adalah ekstrak pucuk daun sirsak.

Pada menit ke-15, muncul area puncak pada ekstrak pucuk daun sirsak dan ekstrak pangkal daun sirsak tetapi tidak muncul pada ekstrak tengah daun sirsak disebabkan kemungkinan karena tidak adanya senyawa pada bagian pangkal daun sirsak. Dapat dilihat komponen senyawa dengan konsentrasi tinggi pada ekstrak pucuk daun sirsak yang dapat dilihat dari luas area ekstrak puck daun sirsak lebih luas.

\section{KESIMPULAN}

Berdasarkan profil kromatogram HPLC, posisi daun memberikan pengaruh terhadap komponen kimia dan bagian pucuk daun memperlihatkan aktivitas antibakteri yang lebih besar dengan diameter zona hambat terhadap Staphylococcus aureus sebesar $12,73 \mathrm{~mm} \pm 0,25$ dan Pseudomonas aeruginosa sebesar $11,83 \mathrm{~mm} \pm 0,65$.. 


\section{DAFTAR PUSTAKA}

1. Cowan MM. Plant Products as Antimicrobial Agents. 1999;12(4):564-82. 2. Muttaqein EZ ST. PATTERN SENSITIVITY OF Staphylococcus aureus TO ANTIBIOTIC PENICILIN PERIOD OF YEAR 2008-2013 IN BANDAR LAMPUNG Muttaqein EZ, Soleha TU. 2013;47-55.

3. Setianingsih $\mathrm{Y}$, Fadraersada I Ibrahim A, Ramadhan AM. POLA RESISTENSI BAKTERI TERHADAP ANTIBIOTIK PADA PASIEN DIABETIC FOOT DI RSUD ABDUL WAHAB SJAHRANIE SAMARINDA PERIODE AGUSTUS-OKTOBER 2016. 2016;20-1.

4. Landman D, Bratu S, Kochar S, Panwar M, Trehan M, Doymaz M, et al. Evolution of antimicrobial resistance among Pseudomonas aeruginosa Acinetobacter baumannii and Klebsiella pneumoniae in Brooklyn , NY 2007;(May):78-82.

5. Foong CP, Hamid RA. Evaluation of anti-infl ammatory activities of ethanolic extract of Annona muricata leaves. 2010:1301-7.

6. Siqueira CAT, Oliani J, Sartoratto A, Queiroga CL, Moreno PRH, Juliana Q et al. Chemical constituents of the volatile oil from leaves of Annona coriacea and in vitro antiprotozoal activity. 2009;33-40.

7. Kim G, Zeng L, Alali F, Rogers LL, Wu F, Mclaughlin JL. Two New MonoTetrahydrofuran Ring Acetogenins , Annomuricin E and Muricapentocin , from the Leaves of Annona muricata. 1998;3864(97):432-6.

8. Abubacker MN, Deepalakshmi T. In vitro Antifungal Potentials of Bioactive Compound Methyl Ester of Hexadecanoic Acid Isolated from Annona muricata Linn . ( Annonaceae ) Leaves. 2013;10(December):879-84.

9. Taylor L. Technical Data Report. 2005;

10. Oyedeji O, Taiwo FO, Ajayi OS, Oziegbe M. Biocidal and Phytochemical Analysis of Leaf Extracts of Annona muricata International Journal of
Sciences: Basic and Applied Research Biocidal and Phytochemical Analysis of Leaf Extracts of Annona muricata ( Linn .). 2015;(December 2018).

11. Pinto NDCC, Campos LM, Carolina A, Evangelista S, Lemos ASO, Silva TP, et al. Industrial Crops \& Products Antimicrobial Annona muricata L . ( soursop ) extract targets the cell membranes of Gram-positive and Gramnegative bacteria. Ind Crop Prod [Internet]. 2017;107(December 2016):332-40. Available from: http://dx.doi.org/10.1016/j.indcrop.2017.05.054

12. Vijayameena C, Subhashini G, Loganayagi M, Ramesh B. Original Research Article Phytochemical screening and assessment of antibacterial activity for the bioactive compounds in Annona muricata. 2013;2(1):1-8.

13. Setyorini HA, Kurniatri AA, Adelina R, Winarsih. Karakterisasi Mutu Ekstrak Daun Sirsak (Annona muricata L .) dari Tiga Tempat Tumbuh. 2016;279-86

14. Li X, Yin Q, Chen W, Wang J, Section E. Solubility of Hydroquinone in Different Solvents from 276.65 K to 345.10 K. 2006;127-9.

15. Lubis F, Suryanto D, Studi P, Sumberdaya M, Pertanian F, Utara US, et al UJI EFEKTIVITAS ANTIMIKROBA EKSTRAK DAUN SIRSAK (Annona muricata L.) TERHADAP BAKTERI Aeromonas hydrophila, Edwarsiella tarda DAN FUNGI Saprolegnia sp. 2015;

16. Sari DL. UJI AKTIVITAS ANTIBAKTERI EKSTRAK ETANOL DAUN SIRSAK MUDA DAN TUA ( Annona muricata L.) TERHADAP Staphylococcus aureus SKRIPSI. 2018;

17. Yovitasari D, Retnaningsih A, Elsyana V. UJI DAYA HAMBAT EKSTRAK DAUN SIRSAK (Annona muricata L.)TERHADAP PERTUMBUHAN BAKTERI Staphylococcus aureus DAN Pseudomonas aeruginosa DENGAN METODE DIFUSI AGAR. 2018;1(1):1-4.

18. Syenina A. VALIDASI METODE KROMATOGRAFI CAIR KINERJA TINGG (KCKT) FASE TERBALIK PADA PENETAPAN KADAR NIKOTIN DALAM EKSTRAK ETANOLIK DAUN TEMBAKAU. 2011 